\title{
Model of Teaching and Learning Management according to the Four Noble Truths for Primary School Students under the Bangkok Metropolitan Administration
}

\author{
Phrakhupalad Sak Mahāvīro (Kosolsuphawat) ${ }^{1}$, Phrakhrusangharak Chakkit Bhuripanyo ${ }^{2 *}$, Peravat \\ Chaisuk $^{3}$, Thongdee Sritragarn ${ }^{4}$ \\ 1,2,3,4 Faculty of Education, Mahachulalongkornrajavidyalaya University \\ 1,2 dews280@hotmail.co.th, ${ }^{3}$ pchaisuk@gmail.com ${ }^{4}$ thongdee.sri@mcu.ac.th
}

\begin{abstract}
The objectives of this research articles were 1) to study problems and obstacles in teaching and learning management according to the Four Noble Truths for primary school students under the Bangkok Metropolitan Administration, 2) to study the process of learning and teaching development according to the Four Noble Truths for primary school students under the Bangkok Metropolitan Administration, and 3) to propose a model of teaching and learning management according to the Four Noble Truths for primary school students under the Bangkok Metropolitan Administration. Mixed methods research was used for the design. Quantitative data was collected from 345 samples and analyzed by descriptive statistics using percentage, mean and standard deviation and qualitative data were collected by interview 10 key informants and focus group discussion with 10 experts. The results of the research showed that 1) conditions, problems and obstacles in teaching and learning according to the Four Noble Truths of primary school students in the Bangkok Metropolitan Administration, it was found in 5 aspects which were (1) curriculum, (2) learning process, (3) learning and teaching materials, (4) learning activities, and (5) assessment. Considering each aspect in descending order showed that learning activity was shown at a high level of opinion. In teaching materials, it was found at a high level of opinion, and the curriculum was at a high level. The learning process was at a moderate level of opinion, and in assessment was at a low level, respectively. 2) The process of learning and teaching development according to the Four Noble Truths through 5development processes which were the 1st Process was suffering (problem determination) problem condition and cause of suffering, the 2 nd process was a cause or hypothesis, development of analysis and the process of finding suffering, the 3rd process was results, collecting data and experimental methods to prove the hypothesis, there was a planning to solve the problem, the 4th process was solution to develop an analysis according to the principle categorize data to classify problems, and the 5th process was to summarize the results of integrated learning with the Four Noble Truths. 3) A model of teaching and learning management according to the Four Noble Truths was proposed 5 STEPS LEARNING which consisted of Model 1 was to search for knowledge, formulate problems and ask questions; Model 2 was to make hypotheses, analyze causes of problems, and seek the cause of suffering particularly teaching form; Model 3 was a method of thinking, creating a learning model in connection with objectives to concept to cause and effect, building knowledge from concept, theory and practice, and distinguish categories sort data that links through various processes; Model 5 was to summarize from 4 models according to the Four Noble Truths which could be utilized for the peaceful integrated Buddhist education for sustainability
\end{abstract}

Keywords

Teaching and Learning, the Four Noble Truths, Bangkok Metropolitan

Article Received: 10 August 2020, Revised: 25 October 2020, Accepted: 18 November 2020

\section{Introduction}

Education is the development of people to be knowledgeable and able to strive for the development of the nation since early childhood is holistically both intelligence moral ethics and technology by developing readiness since the country's educational development structure. It is also a preparation for parenting that is suitable for the development of the brain, intelligence, body and mind that drives learning happily connect what you have learned with your real life and act as a good role model. The public sector wants to provide education in accordance with the real way of life with a focus on quality for young children by encouraging the elderly with potential to participate in enhancing the development of young children to receive an equal education in all sectors of the country will develop schoolage children to have academic knowledge and strong emotional intelligence, able to study and expand knowledge by oneself [1].

Problems in teaching and learning, at present, there are many types of problems. Each of which affects the development of the country and the future of Thai youth whether it is absent from school loss of education and or family problems or present results in the overall study of the country is the problem that gates about the right to dress to school, or the problem of teacher pornography causing the image of Thai teachers to return to the world of deterioration again. All of the above are problems of Thai education management.

Problems and obstacles to learning among students and teaching and learning of teachers, the principles of Buddhism should be integrated into the teaching of teachers as well in order to cultivate the habits for students to be absorbed and put into practice in particular, the Four Noble Truth category is suffering, happiness, occurrence or cause of suffering, anger, an end of suffering and path leading to the cessation of problems and obstacles in teaching and learning, making researchers interested in researching the subject. The teaching and learning management model according to the theory of Four Noble Truth principles to be used as a teaching and learning management model for school students. It may make students happy with their studies and promote and support such policies for maximum 
efficiency in the development of people, also developing students.

\section{Research Objectives}

The objectives of this research articles were 1) to study problems and obstacles in teaching and learning management according to the Four Noble Truths for primary school students under the Bangkok Metropolitan Administration, 2) to study the process of learning and teaching development according to the Four Noble Truths for primary school students under the Bangkok Metropolitan Administration, and 3) to propose a model of teaching and learning management according to the Four Noble Truths for primary school students under the Bangkok Metropolitan Administration.

\section{Research Conceptual Framework}

A model of teaching and learning management according to the Four Noble Truths for primary school students under the Bangkok Metropolitan Administration, the researcher has adopted the concept theories and related research to be consistent with the variables as shown in Fig. 1.

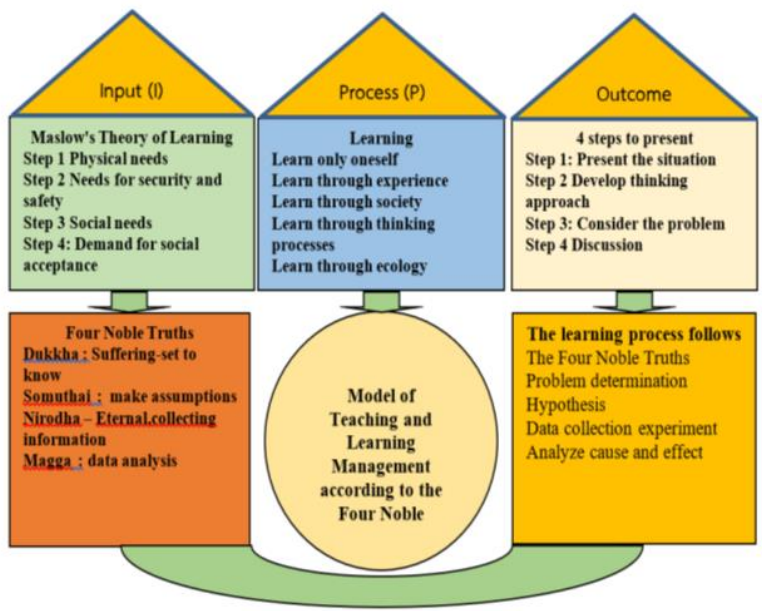

Fig. 1 Conceptual Framework

\section{Research Method}

1. The researcher has been conducting research in Mixed Method Research by using quantitative research methods mainly and qualitative research is supporting research by collecting questionnaires and opinions from teacher's elementary education under Bangkok obtained a sample of 345 people and a qualitative research by interviewing 10 experts to synthesize information on the study issues. To organize a focus group discussion of 10 experts. The research tools consisted of questionnaires, interviews form and issue for focus group discussions.

2. Data analysis and statistics are used for mean and standard deviation, presented in the form of a table with subtitles.

3. Analysis from interviews using the method of content analysis and summarize the data according to the interview form.

\section{Research Findings}

1. The condition of problems and obstacles in teaching and learning according to the principle of Four Noble Truths of primary school students under the Bangkok Metropolitan. Educational management based on problems and obstacles in teaching and learning management in the current state. There are still many problems that the government has not been able to solve and the problems are accessible and relevant from statistical studies. The data from questionnaires were used to analyze problems and obstacles in teaching and learning according to Four Noble Truths, there was a lack of application process and integration, namely 1) curriculum, 2) learning process, 3 ) media learning and teaching, 4) learning activities,

measurement and evaluation. Every issue was studied.

2. The process of teaching and learning management according to the Four Noble Truth principles for elementary school students under Bangkok Metropolitan Administration.

Process 1, Suffering (problem determination), study the problem condition, environment, instructional media and teachers that what are the problems and obstacles? Which is the cause of the suffering problem search. It is a connected thinking practice, and thinking for a cause. The teacher has to point out where the student is coming from, and able to manage to achieve goals was classified as a success.

Process 2: Assumption (cause) or assumptions giving students analyzed to find the root cause of the problem in teaching and learning management, focus on thinking action and cause which is the cause of all suffering by making assumptions for students to participate seek learning together fostering empathy from teachers helping to resolve the problem and be able to find the cause of suffering is the development of the process of finding suffering.

Process 3 Nirodha (Outcome) develop experiments and information gathering whereby teachers should aim for learners to define objectives and how to experiment to prove the hypothesis. It is the development of learning to create a body of knowledge in learning and teaching media, learning by using the principles of the Four Noble Truths as well by starting from the use of different media to categorize it into the path to be used to supplement educational media classified as the path because they can achieve the achievement of their goals.

Process 4 Magga (solution) develop a cause analysis to solve the problem must categorize the data and then come in order classify the problem and analyze it that will lead to solving the problem properly, promote knowledge sharing strengthening morality, generosity, sharing things starting from small things, it is classified as a way of learning with clear solutions that can be managed.

Process 5 Conclusion is one more step of learning development. For the learners to learn the training process by applying knowledge from practice through 4 processes, there is a summary of results, creating work and a team. Cocreate works obtained from solving social problems creatively. It is a body of knowledge that is responsible for society which is an expression of support and share in the society for a sustainable peace. 
3. Propose a teaching and learning management model according to Four Noble Truths principles for primary school students in Bangkok.

The results of the research revealed that the teaching and learning management model according to Four Noble Truths principles was proposed for elementary school students under the Bangkok Metropolitan Administration, obtained from the research can be summarized as a body of knowledge from the research "5 STEPS LEARNING" as follows.

Model 1 is the problem determination model. Learning ask questions or questioning step is a place for students to practice observing the situation various phenomena until the doubt. Then, train the child to ask important questions including answer predictions by searching for knowledge from various sources and summarizing temporary answers.



Fig.2 Shows the relationship of suffering

Model 2 from the study of data and hypotheses having students analyze the cause of the problem and make a hypothesis. Learning seeks the cause of distress from teaching. How did it come about from concept analysis? Theories and expert interviews to synthesize information leading to the design process planning work from various learning sources, including experiments, is a stage where children use the principle of empathy as a mechanism to manage concepts and practices such as pictures.

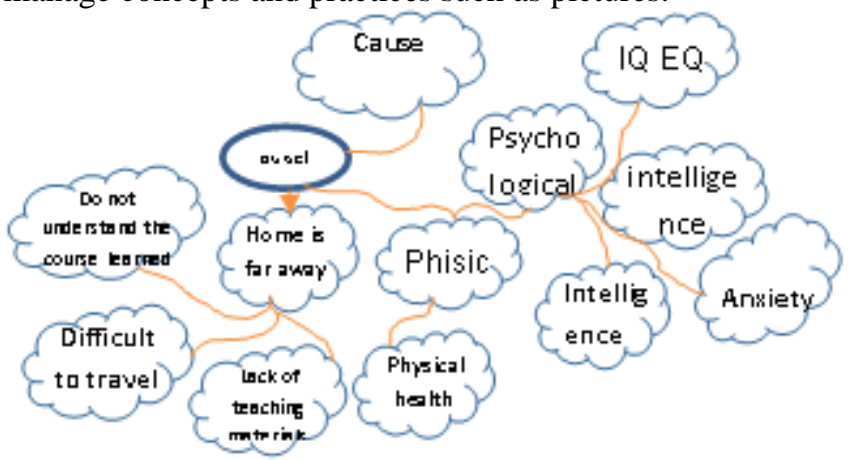

Fig.3 Shows the interrelationships of causes of suffering.

Model 3 from the model experiment the teacher will give you advice since the way of thinking how to do and build a coherent learning model set objectives to prove hypothesis and collect data linking ideas into results from the cause to the success what are the factors that contribute to this success or what are the problems or obstacles that do not meet the objective learning. This style will learn the performance results gather information in different dimensions to summarize or create a picture description. Linking ideas is the building of knowledge from the conceptual principles, theories and empirical practice are shown in Fig.4.



Fig. 4 Shows the relationship between angered learning management (outcome) success.

Model 4 Solution, it is organized to separate the different parts of evidence or information that has been divided into categories to find an answer according to the purpose and according to the assumptions established. When encountering problems and obstacles at work, stick to the concept of how Magga is the solution to the problem, so it will get good results by synthesizing the concept, linking it with different processes as shown in Fig.5.

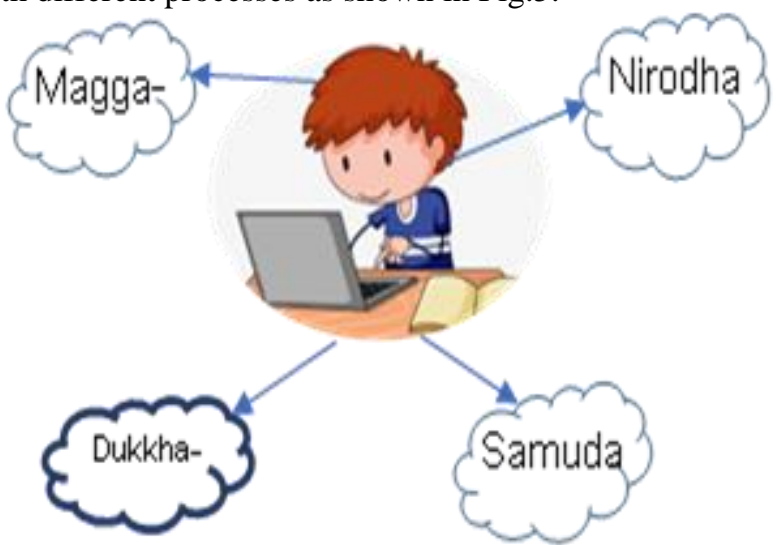

Fig. 5 Shows the relationship between learning with Magga (Solution)

Model 5 is a summary of 4 models according to the Four Noble Truths, which is a model that the researcher has developed in 4 models according to the Four Noble Truths, know to be the process of training children to apply knowledge that is understood and can use learning to benefit oneself and for society as a whole maybe this is another format that can be used by teachers, and share to society with peace and sustainability as in Fig.6. 




Fig.6 Shows the relationship between the four noble truths of learning management.

\section{Discussions}

1. The condition of problems and obstacles in teaching and learning according to the principle of Arithmetic 4 of primary school students. In Bangkok, it was found that

Teaching and learning management according to the Four Noble Truth for elementary school students under Bangkok Metropolitan Administration. In terms of measurement and evaluation, it was found that there was a low level of overall opinion. Considered individually, in descending order of 3 ranks: for individual student development. It is an assessment of the quality, skills, knowledge and understanding of each student. For further development, it is analyzed according to the specified criteria, evaluated in numbers and when considering each item, in descending order of 3 ranks, namely, using the results of the evaluation to clarify and develop in the disadvantage of the students. There are criteria for measuring efficiency. Instructors use observation as a learning evaluation inconsistent with correspondence with Charan Ka-in [3] study problems of teaching and learning of Buddhism. At the secondary school level, Pan District, Lampang Province, it was found that the evaluation was in the low level.

2. The process of learning and teaching development according to the Four Noble Truth principles for elementary school students in Bangkok Metropolitan Administration found that teaching and learning management according to the Four Noble Truth principles for primary school students under Bangkok. Learning management process Provide training for students by switching students who have good behavior to lead fostering attention to learners through various activities to help solve problems of learners.

Teaching and learning media, teacher training or a teacher who teaches the use of media problem solving is planned according to various processes from finding the problem and solving it. This kind of learning is including taking action and organizing activities together, organized as a path for development, using media, organized as a path, organizing various activities to enhance media for education.

For learning activities, educational institutions, community administrators and teachers should set up a policy to promote learning innovation knowledge sharing or share experiences and also to strengthen morality, generosity, sharing things. It starts from small things before it is classified as teaching according to the Four Noble Truths, consistent with Ornong Srichaisuwan has researched on "The effect of using the Four Noble Truths teaching set on learning achievement and problem solving ability of Prathomsuksa 4 students" found that 1) the four Noble Truths teaching set was effective 2 ) The fourth grade students who were managed to learn using the Four Noble Truths teaching set had higher post-experiment achievement than before. There were statistically significant at level. 01 and 3). The fourth grade students who were managed to learn using the Four Noble Truths teaching set. Have a higher problem solving thinking ability than before the experiment. With statistical significance at the .01 level.

3. Propose a teaching and learning management model according to Four Noble Truth principles for primary school students in Bangkok.

1. In the curriculum, the teachers participate in the curriculum drafting. It will meet the needs of the learners and learn the problems of the curriculum and the different contexts of each learner.

2. The learning process, students should be trained by alternating students who have good behavior and problem solving. This section requires cooperation from all parties of the school.

3. Instructional media training for teachers on the use of media, planning to solve problems is angered including taking action for students to develop media use by starting from using simple media first.

4. Learning activities should promote knowledge sharing by clarifying that if the knowledge of each acquired person together to get better knowledge than one person thinks the way.

5. Measurement and evaluation, the teacher has to clarify to the students their weaknesses for further development. Fairly measured and evaluated and measure results in many ways.

All 5 issues are consistent with the research [4] on "The effect of using the Four Noble Truths teaching set on learning achievement and problem solving ability of Prathomsuksa 4 students". Results 1) The Four Noble Truths teaching set was created effectively. 2) Prathomsuksa 4 students who were managed to learn using the Four Noble Truths teaching series had higher post-experiment achievement than before. There were statistically significant at .01 level. and 3) The fourth grade students who were managed to learn using the Four Noble Truths teaching set, have a higher problem solving thinking ability than before the experiment with statistical significance at the .01 level. Amara Roddara, [5] has researched on "The results of teaching the Four Noble Truths on principles on academic achievement and the investigative thinking ability of the sixth grade students at Suriya Uttayapmi Kindergarten, Nakhon Ratchasima Province. The learning achievement of the Dharma of the students learned from the Four Noble Truths teaching methods. The study was statistically significantly higher than before at the .05 level and the investigative thinking ability of the students who learned from the Four Noble Truths teaching methods. The study was significantly higher than before studying at the .05 level. [6] "The Development of Non-School Educational Activities in the Four Noble Truths to Enhance Social Living Skills for Male Inmates in Prisons, in the middle of Chiang Mai Province." Summary of the research results were as follows: 
1. The study of three healing organizations used the framework or approach of the process along the Four Noble Truths, namely the study of the problem of suffering. This is because drug addiction in various forms is the most important stage of family and self-related problems.

2. The development of an activity model based on the Four Noble Truths to enhance life skills is effective. Analysis of case studies of all 3 organizations as a guideline for the development of the model. The principles, objectives, plans of learning activities and training methods are important, aiming for learners to gain knowledge and see valuable life skills, and practice activities according to the neo-humanoid process including organizing physical activities under the framework of the Four Noble Truths.

3. The results of the experiments using an activity model based on the Four Noble Truths were conducted in a group of male inmates who took drugs. Men have a high level of satisfaction in every activities and results from self-assessment showed that most of them continued to do activities every day, such as meditation and brainwave relaxation. Observing the behavior of male inmates during the activities found that they have cooperation and unity, help each other to make decisions in solving group problems with reason, assertiveness, pride in working together responsible and has a relaxed mood.

4. Factors and conditions related to the implementation of the event format. The important factors are facility management, speakers, budget, safety, facilities including organizing activities, promoting morale for inmates is an important factor and condition that will make drug addicts change their behavior to be more valuable to themselves, society, community and nation.

\section{Body Of Knowledge From Research}

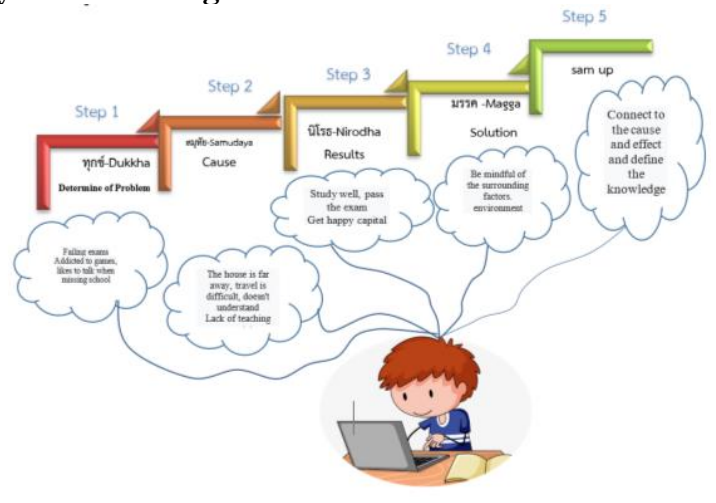

Fig. 7 Model of Teaching and Learning Management according to the Four Noble Truths for Primary School Students under the Bangkok Metropolitan Administration

\section{Recommendations}

\section{Recommendation for policy}

1) Educational institutions should adopt a teaching and learning management model according to the Four Noble Truth principle for elementary school students in Bangkok Metropolitan Administration to use in teaching or apply it integrally to achieve learning that can change the learners' behavior.

2) The teaching and learning management model according to the Four Noble Truth principles should be adopted for elementary school students in Bangkok Metropolitan Administration to use in teaching or apply it integrally to achieve learning that can change the learners' behavior.

\section{Recommendation for further research}

1) Should study the conditions, problems and obstacles in teaching and learning management according to the Four Noble Truths of primary school students in Thai society.

2) Should study the process and develop the teaching and learning management according to the Four Noble Truths through online society for ecological learning.

\section{Conclusion}

The teaching and learning management model according to the Four Noble Truths for primary school students under the Bangkok Metropolitan Administration. Researchers have studied from the concept theories and principles of Buddhism and developed a teaching and learning model according to the Four Noble Truths through the development process by using the Four Noble Truths: Dukkha, Samudaya, Nirodha, and Magga, along with the so called "Works in the Four Noble Truth" consisted of degrees (Determination, Knowing), Pathana (Neglection), Trajikiriya (Enlightening) and Praying (Prosperity or Action), consisting of a process for developing a model and solving a problem (the Suffering stage). The second step is the hypothesis stage (the Samudaya stage), the third step is the experimental stage and the data collection (the Nirodha stage), the fourth step is the data analysis step (the Magga stage).

\section{References}

[1] P. Ployprapai. "Development of a teachingand learning model of thinking in a discriminating component based on Buddhist principles, social wisdom,and experiential learning concepts for trainingkindergarten teachers", Doctor of Science in Science Program and teaching disciplines Graduate School:Chulalongkorn University, 2011.

[2] P. Jaisanit, "Development of a teaching modelbased on the concept of teaching and learning that emphasizes on individual differences to promote the ability to design learning management in the 21st century for teachers students, Rajabhat University ",Doctor of Science in Science Program and teachingfield, Graduate School: Chiang Rai RajabhatUniversity, 2016.

[3] C. Ka-in, "Problems of teaching and learning Buddhism at the lower secondary level Mueang Pan District Lampang 
Province ", Independent research, Master of Science, Graduate School: Chiang Mai University, 1997.

[4] O. Srichaisuwan, The effect of using the FourNoble Truths teaching series on learning achievementand problem solving ability of Prathomsuksa 4students", Research Report in Educational Sciencesand Learning Management. know. Faculty of Education Srinakharinwirot University, 2015.

[5] A. Roddara, "The results of teaching the FourNoble Truths on the principles of learning achievementand Factor-critical thinking ability of elementary school 6 students at Suriya Uthai Phimai Kindergarten, NakhonRatchasima Province ", Research report, Sukhothai Thammathirat Open University, 2009.

[6] Phra Damrong Benjakiri, "Development of Non-SchoolEducation Activities in accordance with the Four NobleTruths to enhance social living skills of male inmates in Prisons, In the middle of Chiang Mai Province ", Doctorof Education Thesis Field of study outside the school 